\title{
Megadroughts in Southwestern North America in ECHO-G Millennial Simulations and Their Comparison to Proxy Drought Reconstructions*
}

\author{
SLOAN COATS \\ Lamont-Doherty Earth Observatory, Columbia University, Palisades, and Department of Earth and Environmental Science, \\ Columbia University, New York, New York \\ JASON E. SMERDON AND RICHARD SEAGER \\ Lamont-Doherty Earth Observatory, Columbia University, Palisades, New York \\ BENJAMIN I. COOK \\ NASA Goddard Institute for Space Studies, New York, and Lamont-Doherty Earth Observatory, Columbia University, \\ Palisades, New York \\ J. F. GONZÁleZ-RouCO \\ Instituto de Geociencias (UCM-CSIC) Facultad de Ciencias Físicas, Universidad Complutense, Madrid, Spain
}

(Manuscript received 3 August 2012, in final form 21 March 2013)

\begin{abstract}
Simulated hydroclimate variability in millennium-length forced transient and control simulations from the ECHAM and the global Hamburg Ocean Primitive Equation (ECHO-G) coupled atmosphere-ocean general circulation model (AOGCM) is analyzed and compared to 1000 years of reconstructed Palmer drought severity index (PDSI) variability from the North American Drought Atlas (NADA). The ability of the model to simulate megadroughts in the North American southwest is evaluated. (NASW: $25^{\circ}-42.5^{\circ} \mathrm{N}$, $\left.125^{\circ}-105^{\circ} \mathrm{W}\right)$. Megadroughts in the ECHO-G AOGCM are found to be similar in duration and magnitude to those estimated from the NADA. The droughts in the forced simulation are not, however, temporally synchronous with those in the paleoclimate record, nor are there significant differences between the drought features simulated in the forced and control runs. These results indicate that model-simulated megadroughts can result from internal variability of the modeled climate system rather than as a response to changes in exogenous forcings. Although the ECHO-G AOGCM is capable of simulating megadroughts through persistent La Niña-like conditions in the tropical Pacific, other mechanisms can produce similarly extreme NASW moisture anomalies in the model. In particular, the lack of low-frequency coherence between NASW soil moisture and simulated modes of climate variability like the El Niño-Southern Oscillation, Pacific decadal oscillation, and Atlantic multidecadal oscillation during identified drought periods suggests that stochastic atmospheric variability can contribute significantly to the occurrence of simulated megadroughts in the NASW. These findings indicate that either an expanded paradigm is needed to understand multidecadal hydroclimate variability in the NASW or AOGCMs may incorrectly simulate the strength and/or dynamics of the connection between NASW hydroclimate variability and the tropical Pacific.
\end{abstract}

* Lamont-Doherty Earth Observatory Publication Number
7701 .

Corresponding author address: Sloan Coats, Lamont-Doherty Earth Observatory, 61 Route 9W, Palisades, NY 10964.

E-mail: sjc2164@columbia.edu

\section{Introduction}

A particularly stark feature of proxy-estimated multidecadal hydroclimate variability in the North American southwest (NASW: $25^{\circ}-42.5^{\circ} \mathrm{N}, 125^{\circ}-105^{\circ} \mathrm{W}$ ) is the occurrence of so called megadroughts [for a review, see Cook et al. (2007)]. Although drought definitions vary, 
a megadrought can be defined as a persistent period of drought conditions lasting decades to centuries. Proxy records indicate the presence of two century-scale megadroughts during the last millennium in the Sierra Nevada (Stine 1994; Cook et al. 2010), as well as a series of multidecadal droughts that impacted much of the NASW (Cook et al. 2007; Herweijer et al. 2007). Understanding the cause of these megadroughts is important because of the potential for similarly extreme drought periods to emerge in the future. The presence of such drought regimes in the past (Woodhouse and Overpeck 1998; Cook et al. 2010; Herweijer et al. 2007) is particularly sobering when considering the current vulnerability of the NASW water supply to hydroclimate change (e.g., Schlenker et al. 2007).

Assessing the ability of atmosphere-ocean general circulation models (AOGCMs) to simulate multidecadal drought features, like megadroughts in the NASW, is critical because these same models are used to make twenty-first-century climate projections. For example, the ensemble of International Panel on Climate Change (IPCC) Fourth Assessment Report (AR4) models project widespread drying in the subtropics over the coming century (Pachauri and Reisinger 2007; Seager and Vecchi 2010). While this has been established as a forced response to increasing greenhouse gas concentrations in the atmosphere, it is unclear how forced and internal variability contribute to persistent hydroclimate features like past megadroughts. Determining the relative contribution is necessary because future hydroclimate will be determined by both radiatively forced changes and interannual-to-multidecadal internal variability. Hydroclimate projections and associated risk assessments, therefore, require that AOGCMs capture both forced change and the amplitude and character of internal variability. Furthermore, the ratio of internal to forced hydroclimate variability in the NASW has consequences for the predictability of future hydroclimate, particularly hydroclimate change related to anthropogenic greenhouse gas forcing.

Despite the importance of testing the validity of simulated variability in NASW hydroclimate on decadalto-centennial time scales, it is difficult to do so with the instrumental record alone, therefore necessitating the use of paleoclimate estimates of past variability as model targets. Paleo model-data comparisons are thus vital exercises for evaluation of future hydroclimate projections. The approach and execution of such comparisons will be investigated in this paper using millenniumlength simulations from the ECHAM and the global Hamburg Ocean Primitive Equation (ECHO-G) AOGCM (González-Rouco et al. 2006) and the North American Drought Atlas (NADA) (Cook et al. 2007).
A wealth of research has implicated tropical sea surface temperatures (SSTs) as the dominant forcing of drought in the NASW. Schubert et al. $(2004 \mathrm{~b}, \mathrm{a})$, for instance, simulated the 1930s Dust Bowl drought as a response to tropical Atlantic and Pacific SST anomalies. Seager et al. (2005) and Herweijer et al. (2006) subsequently reproduced all of the major droughts of the nineteenth and twentieth centuries using an atmospheric general circulation model (AGCM) forced with observed SSTs. Similarly, Seager et al. (2008a) simulated megadroughts during the Medieval Climate Anomaly (MCA) with an AGCM forced with SSTs estimated from a single tropical Pacific coral record (Cobb et al. 2003). These simulated megadroughts were analyzed by Burgman et al. (2010), who noted similarities between the global pattern of modeled MCA hydroclimate and the one estimated from paleoclimate proxies. Herweijer et al. (2007) further analyzed megadroughts in the paleoclimate record, employing tree-ring reconstructions from the NADA to compare modern droughts to the megadroughts of the MCA. They proposed that the well-documented El Niño-Southern Oscillation (ENSO)-NASW teleconnection of the modern period (e.g., Seager et al. 2005; Herweijer et al. 2006) was the likely forcing of persistent drought during the MCA, with the difference in drought persistence arising from the duration of drought-favorable SST conditions in the tropical Pacific. Similar work from Graham et al. (2007), using multiproxy and modeling methods, also implicates the tropical Pacific along with Indian Ocean SSTs as the principal influences on MCA hydroclimate changes. More recently, Feng et al. (2008) and Oglesby et al. (2011) have suggested that the tropical Atlantic played a role in forcing the MCA megadroughts, while Cook et al. (2013) have argued for the importance of dust aerosol forcing on both the spatial character and persistence of droughts in North America during the 1930s Dust Bowl and MCA droughts.

Research has also placed the tropical Pacific SST boundary forcing in the context of model projections of global warming. Cook et al. (2010), for instance, recognize that, although the IPCC AR4 models robustly predict a shift toward dry conditions in the NASW, there is no agreement on the future state of the tropical Pacific, despite the strong connection between ENSO and NASW hydroclimate. This is because predicted drying arises not by any change in the spatial patterns of tropical SSTs but rather by overall planetary warming (Seager et al. 2007). Seager and Vecchi (2010), however, note that models that simulate an increase in the tropical Pacific east-west SST gradient (i.e., a trend toward more La Niña-like conditions) produce more drying in the NASW than those that simulate a decrease in the gradient. Recent work 
nevertheless has complicated the gradient picture by demonstrating a large degree of internal variability of the zonal gradient in AOGCMs at centennial time scales (Karnauskas et al. 2012).

Despite the large collection of literature in related areas, there are few analyses of megadrought occurrences and characteristics in simulations using AOGCMs. Meehl and $\mathrm{Hu}$ (2006, hereafter MH06) used a 1000-yr control run from the National Center for Atmospheric Research (NCAR) Parallel Climate Model (PCM) fully coupled AOGCM and found drought features of comparable length to proxy-estimated megadroughts that are mechanistically linked to low-frequency variability in tropical Pacific SSTs. Additionally, Hunt (2011) analyzes global multiyear drought and pluvial occurrences in a 10000-yr control run of the CSIRO AOGCM and finds that persistent hydroclimate features can result from internal climatic variability, with stochastic atmospheric variability playing an important role.

The following study builds on the work of MH06, Hunt (2011), and Herweijer et al. (2007) but differs in that we analyze both a forced transient millenniumlength simulation and a 1000-yr control run together with 1000 years of proxy-estimated drought conditions. Two principal questions are addressed: 1) is the model capable of producing megadroughts that are characteristic of the paleoclimate record and 2), if so, are these drought features the result of internal variability or do they have a forced component? Answering these questions is fundamental to understanding megadrought dynamics and interpreting simulations of future hydroclimate variability, which are in turn essential for future water supply management, risk assessment and infrastructure development in the NASW.

\section{Data and methods}

\section{a. Observed and paleoclimate data}

Reconstructed PDSI data are from the North American Drought Atlas (NADA) version 2a: the full details of which can be found in Cook et al. (2007). The data are reconstructed on a $2.5^{\circ}$ latitude $\times 2.5^{\circ}$ longitude grid of summer [June-August (JJA)] average PDSI values for the United States, as well as southwestern Canada and northern Mexico (286 grid points in total). The summer PDSI is reconstructed from a network of 1854 annual tree-ring records using a nested point-by-point regression method to produce records of maximal length. Verification statistics indicate that all grid points for the chosen analysis period (1000-1989 CE) and region $\left(25^{\circ}-42.5^{\circ} \mathrm{N}\right.$, $125^{\circ}-105^{\circ} \mathrm{W}$ ) are highly statistically significant (decadal values of multiple determination, reduction of error, and coefficient of efficiency are greater than 0.7 for a 33-yr verification interval over California and Nevada; Cook et al. 2010). We also use SST data from the Kaplan extended SST V2 product, which is a $5^{\circ}$ latitude $\times 5^{\circ}$ longitude gridded SST field for the period 1856-present (Kaplan et al. 1998).

\section{b. Model}

Model analyses are performed using output from the ECHO-G AOGCM that combines the ECHAM4 and Hamburg Ocean Primitive Equation global (HOPE-G) atmospheric and ocean models, respectively (Legutke and Voss 1999). The resolution of the atmosphere is T30 horizontal $\left(3.75^{\circ}\right)$ by 19 vertical levels, while the ocean resolution is $2.8^{\circ}$ in the zonal direction (T42) with equatorial refinement in the meridional direction that varies from $2.8^{\circ}$ latitude at the poles to $0.5^{\circ}$ at the equator with 20 vertical levels. The model employs a time-invariant adjustment of heat and freshwater fluxes. We use model SSTs, 2-m surface air temperature (SAT), precipitation, evaporation, sea level pressure, and soil moisture. The ECHO-G soil moisture model component is a single-layer bucket model with reservoir capacity varying based on soil type (Legutke and Voss 1999). For our purposes herein, the SAT, precipitation, and soil moisture are regridded from their native resolution to an even $2.5^{\circ} \times 2.5^{\circ}$ grid.

We use two ECHO-G simulations. The first is a 1000 -yr control simulation (clipped to $989 \mathrm{yr}$ to match the length of the forced simulation used herein) that is run with constant external forcing set to mid-twentiethcentury conditions. The second simulation is the ERIK2 forced transient run (González-Rouco et al. 2006) spanning 990 years (1000-1990 CE; note that our subsequent analyses are over 989 years, 1000-1989 CE, owing to the employed yearly averaging interval of OctoberSeptember) and driven by an estimated suite of external forcing factors including radiative effects of volcanic aerosols, concentrations of atmospheric constituents, and solar irradiance (Zorita et al. 2005). The run was initialized with pre-twentieth-century conditions and spun up for 100 years to the historical forcing of 1000 CE (González-Rouco et al. 2006).

Internal variability of 2-m SAT, sea level pressure (SLP), and precipitation in the ECHO-G control run was evaluated by Min et al. (2005a), who demonstrate that the model is capable of producing overall observed variability for all three of these variables. In a companion paper, Min et al. (2005b) addressed the model treatment of interannual to decadal-scale internal variability using the same control run. They found that ENSO in the ECHO-G model exhibits stronger than observed amplitude and is too frequent and regular, with an 
excessive spectral peak at $2 \mathrm{yr}$ and muted variability in the 3-9-yr range. Importantly, the model produces reasonable ENSO spatial structures and teleconnections (Min et al. 2005b). Collectively, the ECHO-G simulations have been extensively analyzed (e.g., von Storch et al. 2004; Zorita et al. 2003; Stevens et al. 2007; GonzálezRouco et al. 2009; Karnauskas et al. 2012). Thus, despite the limited resolution of the ECHO-G model, its well characterized and vetted performance, and the availability of both millennium-length forced and control runs, make the EHCO-G simulations a comprehensive and consistent framework for an initial assessment of coupled atmosphere-ocean dynamics on decadal time scales.

\section{c. Drought variables}

For historical reconstructed estimates of NASW hydrological conditions, we use PDSI from the NADA. For modeled drought conditions we use soil moisture (normalized over the length of the simulation) from the ECHO-G forced and control model runs. We use annually averaged soil moisture from the model, while the paleo-estimated NADA PDSI represents a JJA average. There were three principal motivations for using the yearly averaged soil moisture instead of the JJA average or the model derived PDSI. First, annual-mean soil moisture provides a wide enough temporal window for addressing megadroughts and their dynamical causes. In particular, droughts driven by winter precipitation in the ECHO-G model (as are common for the NASW) will not necessarily produce a strong hydroclimate signal in the summer (JJA) average soil moisture (the modeled soil moisture memory time scale is $4-5$ months versus $12-18$ months for the PDSI). Second, soil moisture is the model variable of most direct physical relevance to drought. Third, the PDSI appears to have a potentially troublesome dependence on temperature that causes a strong drift toward negative values in the model during the twentieth century, which is in neither the NADA PDSI nor the model soil moisture. The negative drift of PDSI in the ECHO-G model is likely a consequence of the temperature dependence of the Thornthwaite equation for potential evaporation used in the PDSI calculation and the excessive contemporary temperature trends in the model. Similar issues with the temperature dependence of PDSI have been raised in the literature (Sheffield et al. 2012; Burke and Brown 2008; Milly and Dunne 2010). Normalized soil moisture is thus chosen as it provides a comparable analog to the PDSI, which is intended to represent a locally normalized anomaly of moisture supply and demand (Dai et al. 1998, 2004).

Although the simple bucket soil moisture scheme in the ECHO-G model may be problematic, soil moisture captures the influence of temperature and precipitation variability (see the subsequent variable comparison section) and considers snow water storage and melt, water interception by vegetation during rain or snowmelt episodes (skin reservoir), and water infiltration and runoff (Dümenil and Todini 1992). Nevertheless, it must be noted that more complicated soil vegetation atmosphere transfer (SVAT) schemes have the potential to alter results.

\section{d. Drought indices}

A drought index was calculated for the NASW by spatially averaging the normalized grid point anomalies of soil moisture for the NASW region. This box is somewhat more restricted than that of MH06 and Herweijer et al. (2007) in order to maintain a homogeneous sample area (as determined by analyses of the spatial variance of the soil moisture field in the forced and control model runs).

Drought definitions vary in terms of both input data (e.g., PDSI versus precipitation in the observed record) and criteria. We employ a drought definition similar to that described in Herweijer et al. (2007), with a drought commencing after two consecutive years of negative soil moisture anomalies and continuing until two consecutive years of positive anomalies (2S2E). Herweijer et al. required one year to start a drought and included a criterion based on spatial extent, which is not used herein. The adopted definition is different but broadly consistent (see section 3) with the drought definition of MH06, who define drought as consistently negative anomalies in an 11-yr running mean time series of box average precipitation (droughts begin with the first year of anomalously negative precipitation and end in the first year of anomalously positive precipitation in the filtered time series).

Droughts identified using the $2 \mathrm{~S} 2 \mathrm{E}$ definition were ordered by creating a drought density rank. For each drought period, the NASW index was summed from the first to the last year of the drought. These values were subsequently ranked by the negative value of the sum. This drought density ranking was chosen over a purely length-based ranking in order to incorporate both the persistence and severity of each drought.

\section{e. Variable comparison}

The annually and spatially averaged normalized precipitation, precipitation minus evaporation $(P-E)$, and soil moisture over the NASW region are highly correlated in the model simulations (e.g., there is a 0.86 correlation between the soil moisture and precipitation NASW indices). Furthermore, yearly averaged soil moisture closely resembles the JJA average soil moisture for the ECHO-G model with a correlation of 0.7 between 

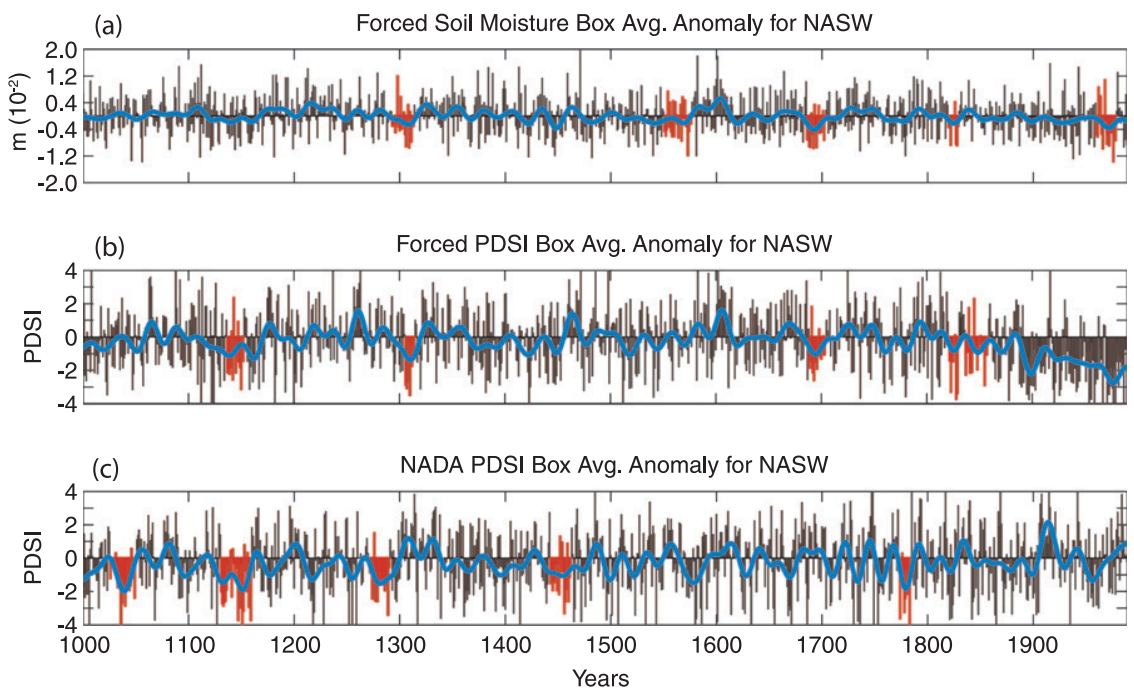

FIG. 1. NASW $\left(25^{\circ}-40^{\circ} \mathrm{N}, 125^{\circ}-105^{\circ} \mathrm{W}\right)$ box averaged (a) unnormalized forced soil moisture (m) and (b) forced PDSI (nondimensional) for the period 1000-1989 from the ECHO-G simulations (standardized over the period 1000-1850). (c) The NADA PDSI (nondimensional) for the same NASW region (standardized over the period 1931-90 using instrumental PDSI). The soil moisture is a yearly average, while the PDSI is a JJA average (again to match the NADA). The five most severe droughts using the described classification and ranking methods in section $2 \mathrm{c}$ are highlighted in red, with the 20-yr low-pass filtered time series plotted in blue.

the two indices for the control run. The use of yearly average soil moisture is further justified by the agreement between the droughts identified in the annual and JJA control soil moisture indices ( 8 of the 10 largest droughts in the control run are in agreement using the drought identification and ranking methodology outlined in the above section for the annual and JJA soil moisture).

We also calculated model PDSI to allow for a direct comparison between simulated soil moisture and PDSI variability in the ECHO-G model (following Cook et al. 2013). Model PDSI is derived on an even $2.5^{\circ} \times 2.5^{\circ}$ grid using simulated precipitation and surface temperature as inputs. At each grid point PDSI was calculated and then standardized against a preindustrial normalization period (1000-1850 CE). Soil moisture capacity was specified as 25.4 and $127 \mathrm{~mm}$ in the top and bottom layers, respectively, and evapotranspiration was calculated using surface temperature via the Thornthwaite (1948) method. The evolution of JJA PDSI is found to be comparable to yearly average soil moisture with three out of the five identified most severe droughts in agreement for the forced run (as can be seen in Fig. 1).

\section{Results and discussion}

\section{a. Analyses of drought indices}

Figure 1 compares the simulated soil moisture in the forced model run to the simulated PDSI and proxy reconstructed PDSI. The simulated NASW soil moisture variability in the ECHO-G model correlates well $(r=0.75)$ with calculated model PDSI during the 10001900 period. The two records diverge in the postindustrial period owing to an unrealistically large negative twentieth-century PDSI trend in the model simulation that can be attributed to an excessively positive temperature trend-more than twice the observed trendand slightly negative precipitation trend in the twentieth century. If the modern/postindustrial period is neglected, the identified droughts using the two variables are consistent in three out of five cases. The exceptions are the late 1500s drought, which is the least severe of the five droughts identified in the soil moisture time series, and the twelfth-century drought in the PDSI time series; this latter drought is present but much smaller in magnitude for the soil moisture time series (and thus not identified as one of the five largest droughts in the time series). The disagreements in drought timing and magnitude seem to be associated with strong temperature controls on calculated PDSI that are not reflected in the modeled soil moisture response. This can be observed most dramatically in the PDSI estimates for the twentieth century in the forced run.

In terms of drought severity, the model exhibits approximately as much interannual and longer time-scale PDSI variability in the NASW region as the proxy record (see the bottom two panels of Fig. 1). Although the PDSI has been noted to be difficult to compare in an 

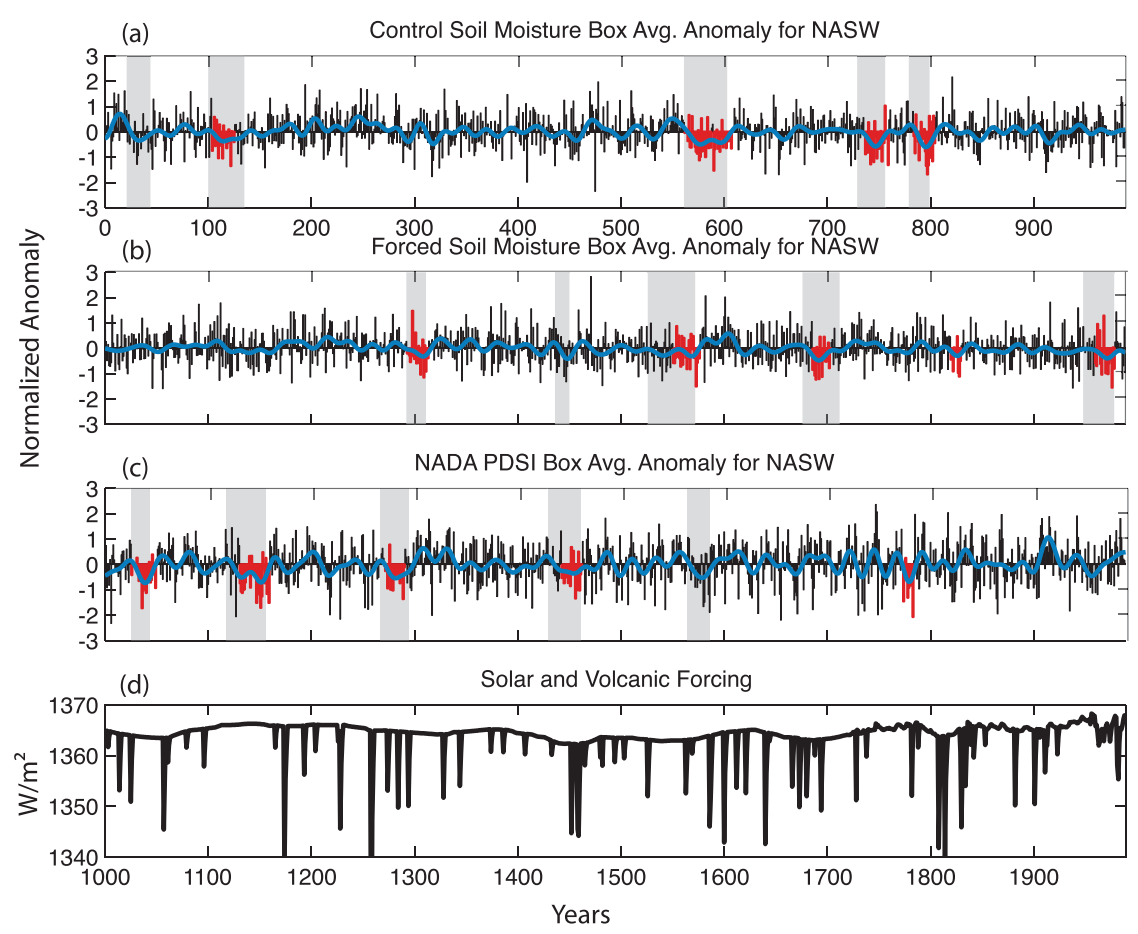

FIG. 2. Normalized soil moisture anomalies (forced and control model runs) and PDSI (NADA) for the period 1000-1989 CE averaged over the NASW region $\left(25^{\circ}-42.5^{\circ} \mathrm{N}, 125^{\circ}-\right.$ $105^{\circ} \mathrm{W}$ ): (a) the control soil moisture index, (b) the forced soil moisture index, and (c) the NADA PDSI index. Annual anomalies (black lines) are shown along with smoothed versions using a 20-yr low-pass filter (blue lines). The red highlighted periods in the annual time series are the five largest droughts as determined by the 2S2E drought definition and the drought density ranking. The gray shaded regions are the five largest droughts determined by the MH06 drought definition. Note that the drought in the sixth century of the control run is actually split into two droughts using the 2S2E drought definition. The gray shaded drought in the first century of the control run is thus the sixth largest drought using our drought definition. (d) The volcanic and solar forcing time series $\left(\mathrm{W} \mathrm{m}^{-2}\right.$ ) used in the forced ECHO-G run for comparison to forced and NADA drought timing. Note that the bottom three panels are for the 1000-1989 CE period; the timing of the control run in (a) is arbitrary.

absolute sense (Dai et al. 1998, 2004), the model megadroughts appear similar in severity to those in the paleoclimate record. An analogous comparison between the forced and control simulations indicates that soil moisture variability is comparable in each. In particular, both model simulations have the same soil moisture variance in the NASW $\left(30.25 \mathrm{~mm}^{2}\right)$. Subsequent comparisons of forced and control responses in normalized soil moisture time series, therefore, can be interpreted as equivalent in their range of variance and can be compared to the proxy-estimated PDSI time series.

Figures $2 \mathrm{a}-\mathrm{c}$ show the time series of the normalized soil moisture anomaly averaged in the NASW box for the forced and control simulations and the NADA PDSI. Using drought density, the five largest droughts were ranked by both the 2S2E (highlighted in red) and MH06 negative running mean index (gray shaded regions). Note that the drought occurring near the end of the 500th year of the control simulation is split into two distinct drought features using the 2S2E metric. Our definition, when ranked by drought density, is consistent with the MH06 definition for 12 out of the 15 droughts ( 4 out of 5 for each dataset). There are slight differences in defined length because filtering removes positive excursions in the MH06 definition that would delay or end droughts using unfiltered data in our 2S2E drought definition. Despite this, it is clear that both drought definitions are identifying the largest negative excursions in the indices. Any discrepancies occur because of a ranking reversal of the fifth and sixth droughts (in the NADA and forced run) or the division of a persistent period of drought into two droughts (in the control run).

\section{b. Paleo model-data comparison}

There is little or no agreement in timing between droughts in the forced simulation and the NADA PDSI 

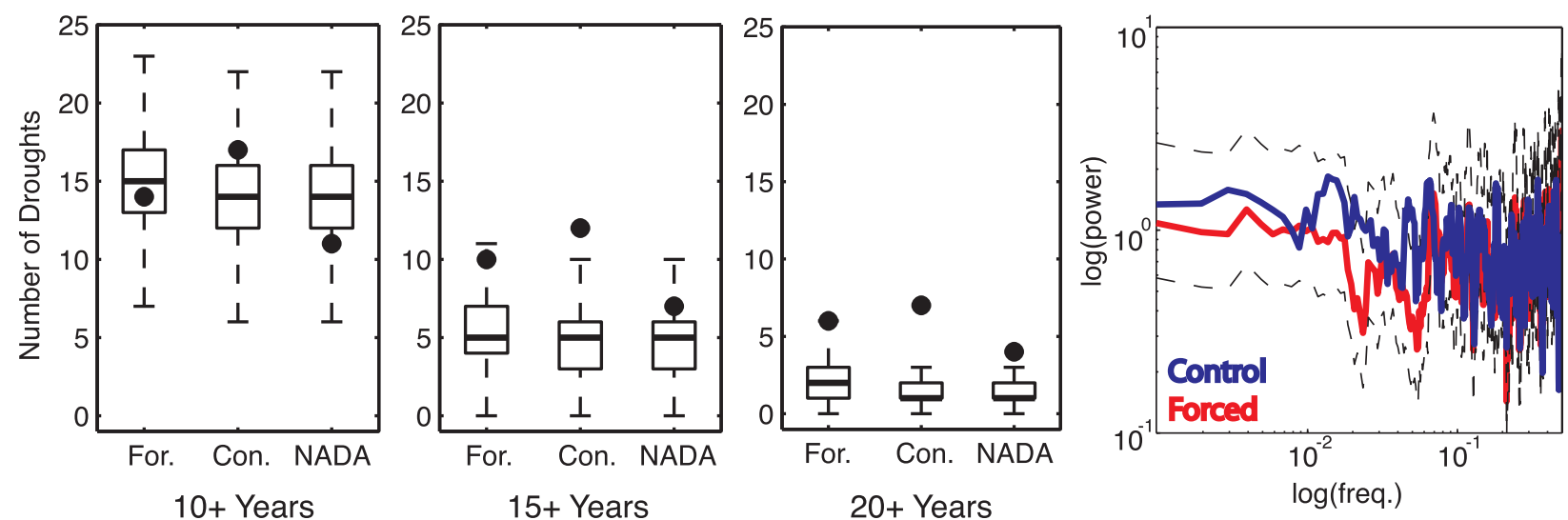

FIG. 3. The black dots are the number of droughts in the NASW region in the forced (For) and control (Con) simulations and the NADA that are at least (from left to right) 10,15, or $20 \mathrm{yr}$ in duration. Box plots are determined from 1000 red-noise time series with the same statistics as the corresponding model or NADA indices (middle bar is mean, top and bottom bars are the 75th and 25th percentiles, and the whiskers are the full data range). (far right) The spectra using the multitaper method (Mann and Lees 1996) for the forced (red) and control (blue) soil moisture indices. The dashed lines are the 5th and 95th percentile confidence intervals for the forced multitaper spectrum.

indices. There are, however, droughts in both control and forced runs that are characteristic of the proxy estimates. In particular, the three time series in Figs. 2a-c demonstrate that megadroughts in both model runs are of comparable duration to those of the paleoclimate record. Although the model exhibits more positive excursions during a given drought period in some cases, the average length of the five most severe forced and control-run droughts is approximately equal to that of the NADA estimates $(19,22$, and $21 \mathrm{yr}$, respectively).

The presence of droughts in the control run that are comparable in length and severity to the forced run suggests that internal climate variability can cause megadroughts in the model. Although it is unclear if observed megadroughts are the result of radiative forcing, overlap between the forced model and proxy-estimated drought time series would be expected if the reconstructed forcing used to drive the model is realistic and the modeled megadroughts are a forced response. This is not the case. For instance, the low-pass correlation between the forced drought index and NADA PDSI index (0.023) is not significantly different from the range of low-pass correlations between the forced drought index and 1000 red noise series with the same persistence as the NADA PDSI index ( $r=-0.014$ and $r=0.075$ are the 25th and 75th percentiles, respectively). Furthermore, the control drought index is just as temporally synchronous with the NADA record as the forced drought index, also indicating that any overlap between the historical droughts and those in the forced run occur by chance. Finally, a direct comparison to the forcing time series can be made in Fig. 2d, which indicates that modeled megadroughts do not have a preferred forcing state. For instance, the 1800 s model drought occurs during a period of relatively low solar forcing and high volcanic activity while the 1300 s and 1500 s model droughts are contemporaneous with relatively high solar forcing and low volcanic activity. These results provide evidence that low-frequency NASW hydroclimate variability in the ECHO-G simulations is not solely a response to radiative forcing changes.

As a further line of inquiry, the numbers of droughts greater than a threshold length are plotted in Fig. 3. The model produces more droughts in each threshold length than the NADA record, but the number of droughts in the model and NADA fall within a narrow range. Also in Fig. 3, the droughts in each dataset are compared to those of 1000 red-noise time series with the same characteristics as the corresponding model or observation (i.e., first-order autoregressive coefficient, variance, and mean). Historical and modeled droughts are more prevalent than those in the red-noise time series for longer time scales (greater than the 90th percentile for all three datasets for droughts of $15+$ and $20+y r$ ) but not for the 10-yr threshold (Fig. 3). This latter observation is not surprising as noise series with some persistence should be capable of producing periods of persistent negative anomalies. The greater drought persistence in the observed and modeled data for longer time scales nevertheless indicates that there are likely mechanisms creating persistence beyond first-order autoregressive variations that are responsible for megadrought occurrences. Interestingly, the box plots indicate that there is more persistent drought in the control simulation than in the forced simulation. A comparison of the spectra of the control and forced drought indices (Fig. 3) suggests 

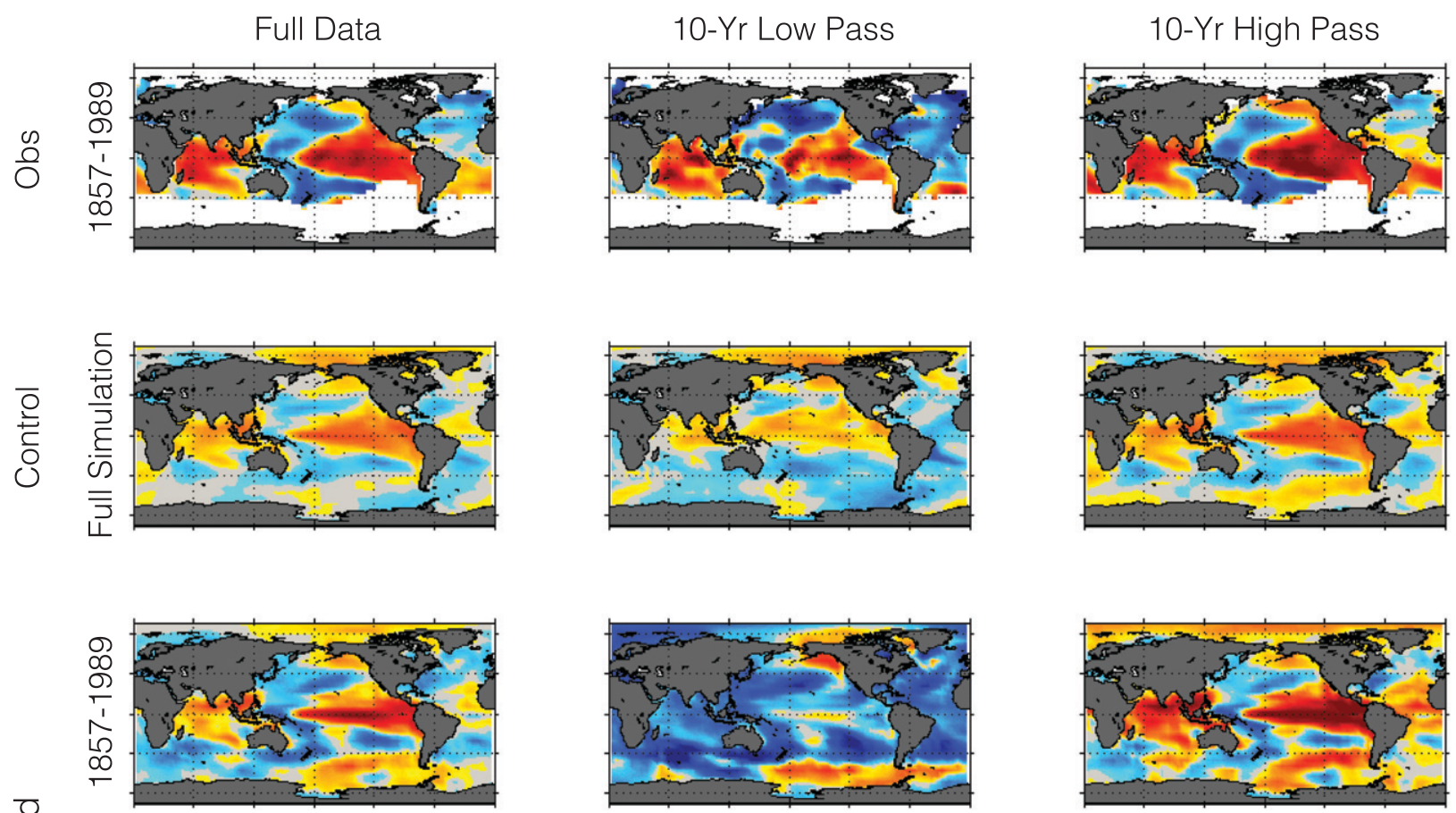

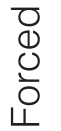
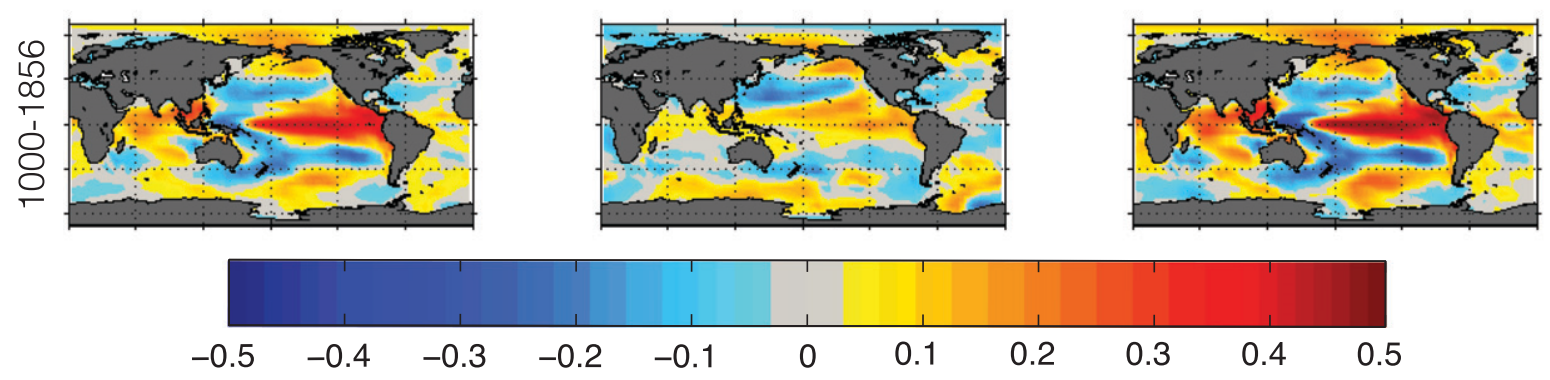

Correlation Coefficient

FIG. 4. Correlation coefficient maps between soil moisture (models) or PDSI (NADA) NASW indices and SST fields. (from top to bottom) The correlation of the overlapping period of the NADA with the Kaplan SST dataset, the full control simulation, the forced simulation for the modern period (1857-1989 CE), and the forced simulation for the period 1000-1856 CE. (left) The full unprocessed data, (middle) the 10-yr low-pass-filtered data, and (right) the 10-yr high-pass filtered data. The forced run was split into two sections because a strong positive trend in eastern Pacific SSTs in the modern period (1870-1989 CE) coincides with a slightly negative trend in the forced soil moisture index and washes out the phase connection between the two fields.

that the control run does in fact exhibit more power in the decadal to multidecadal range.

\section{c. Drought spatial patterns and teleconnections}

To investigate the influence of the tropical Pacific on drought variability in the NASW, we calculate the correlation of the yearly SST field with the NASW drought index: the former was averaged from May to April, and for the model output the latter was averaged from October to September to reflect a lag between the ENSO-driven precipitation anomaly and the soil moisture anomaly (the NADA PDSI is JJA average). These calculations were performed for the full period in the two model simulations and the 133-yr time overlap between the NADA and Kaplan SST datasets (18571989). Three analyses were completed: one with the raw data, one with the 10-yr low-passed data, and one with the high-pass filtered data (separated using a 10-point Butterworth filter). Results are shown in Fig. 4. The NASW region has a weaker connection to the tropical Pacific in the annual and high pass for both the forced and control runs than in the observational data (see Table 1 for the average correlation value in the Niño-3 region). Despite the discrepancy, the model index is still 
TABLE 1. Average correlation coefficients in the Niño-3 region between sea surface temperature and NASW box average soil moisture (ECHO-G) and PDSI (NADA). The full correlationcoefficient field is shown in Fig. 5.

\begin{tabular}{lcccc}
\hline \hline & $\begin{array}{c}\text { NADA/Kaplan } \\
(1857-1989)\end{array}$ & $\begin{array}{c}\text { Forced } \\
(1000-1856)\end{array}$ & $\begin{array}{c}\text { Forced } \\
(1857-1989)\end{array}$ & Control \\
\hline Full & 0.420 & 0.403 & 0.449 & 0.238 \\
High & 0.435 & 0.444 & 0.512 & 0.266 \\
Low & 0.357 & 0.155 & -0.030 & 0.116 \\
\hline
\end{tabular}

highly correlated with the tropical Pacific. Furthermore, it captures the major spatial features of the observed correlation map, indicating that the model contains realistic though weaker teleconnections.

The low-pass correlation map is relevant for the purpose of understanding what drives multidecadal drought variability. For the observations, the connection of NASW PDSI to the tropical Pacific is only slightly lower for lowfrequency variations as compared to high-frequency variations. In the model simulations the control run maintains a connection to the tropical Pacific when lowpass filtered data are used (similar to MH06). The forced run, on the other hand, does not maintain this connection; this results from a strong positive trend in eastern Pacific SSTs in the modern period (1870-1989) that coincides with a slightly negative trend in the forced soil moisture index and washes out the phase connection between the two fields. With the modern period removed there is a moderately positive correlation for low frequencies in the tropical Pacific, but still much weaker than the observational record (the average correlation between NASW soil moisture and Niño-3 SSTs is 0.16 in the forced run versus 0.36 for the paleo-observed record). The frequency dependent relationships are further illustrated in Fig. 5 in which the wavelet coherence of the NASW box average NADA PDSI and the Niño-3 index is shown for the full $133 \mathrm{yr}$ of the instrumental period. Shown below the instrumental plot are wavelet coherence spectra between three randomly selected 133 -yr segments of soil moisture and the corresponding Niño3 SST indices from the ECHO-G control run. As was seen in the correlation fields, the model clearly exhibits much less coherence in the decadal time range than the observations. Note that the low-pass filtered observations also show a relationship between positive PDSI

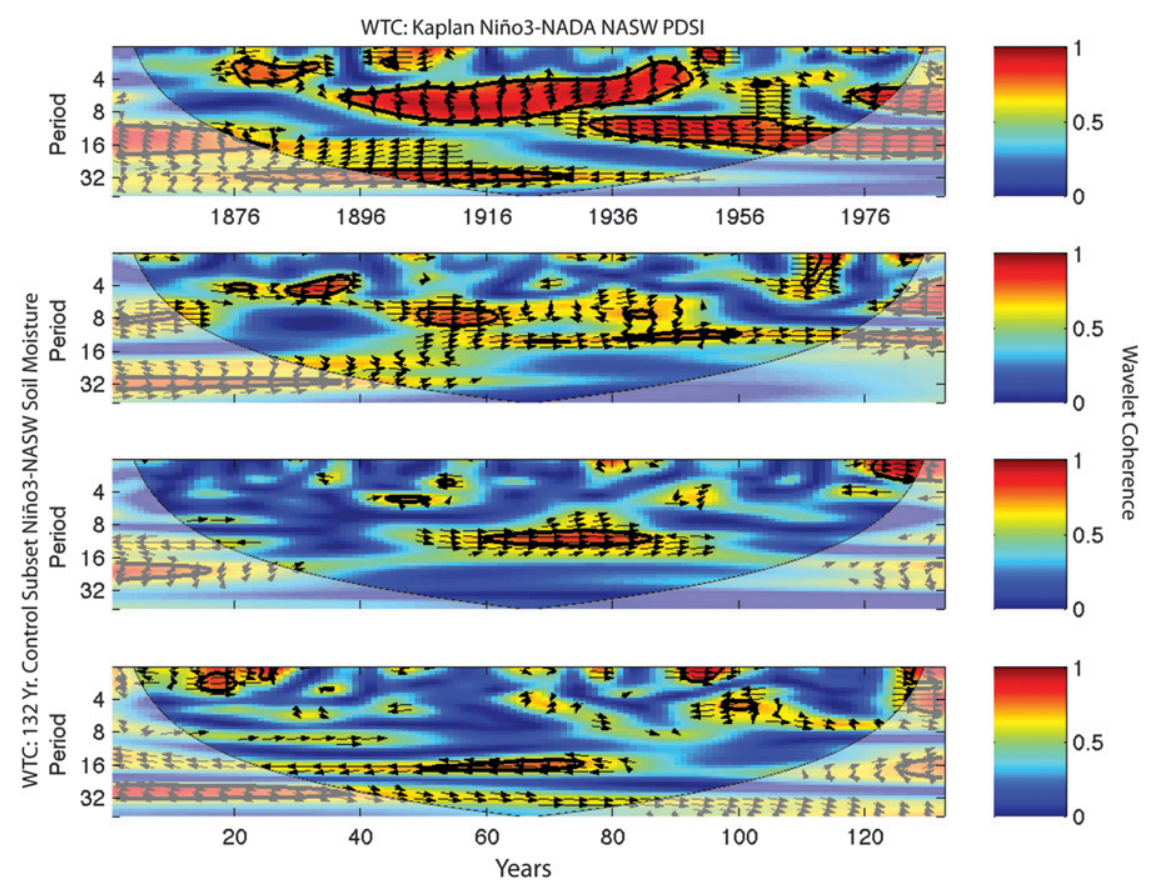

FIG. 5. (top) Wavelet coherence of NASW box average PDSI from the NADA (JJA average) with Niño-3 box average SST (averaged May-Apr) over the common period 1857-1989 CE. (lower panels) Coherence of NASW average soil moisture (averaged Oct-Sep) and Niño-3 SST (averaged May-Apr) for three random 133-yr subsets of the control run. The arrows show the phasing direction, the colored contours show the magnitude of the coherence, and the black outline shows significance at the $95 \%$ level. Shaded regions are outside the significance windows. Note the higher coherence in the decadal range for the observed/proxy data in the top panel. 
Forced: $1686-1703$

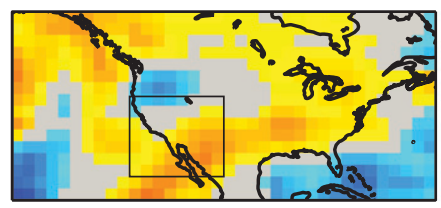

Forced: $1293-1313$

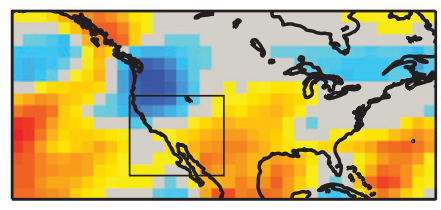

Control: $736-759$

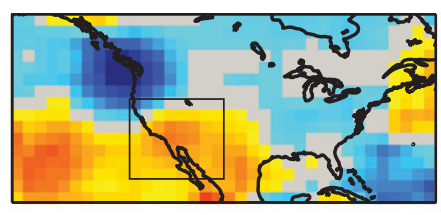

Control: 590-607

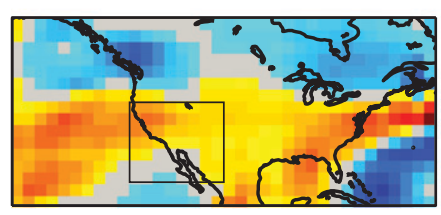

Forced: $1960-1978$

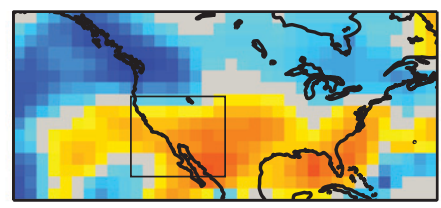

Forced: $1820-1829$

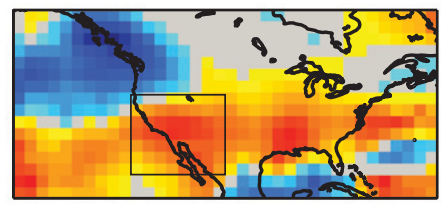

Control: $562-587$

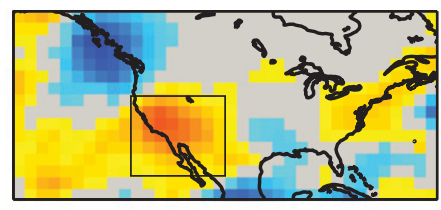

Control: $104-125$

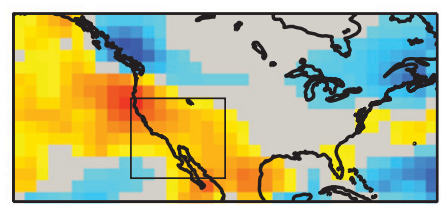

Forced: 1551-1576

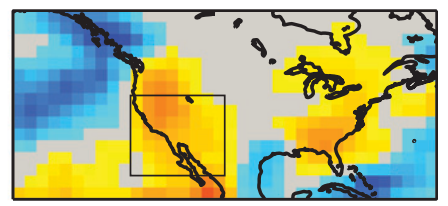

Forced: Composite

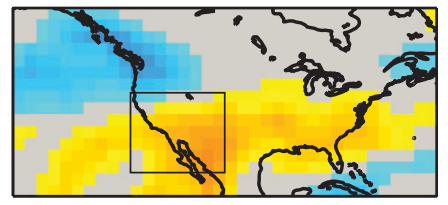

Control: $784-804$

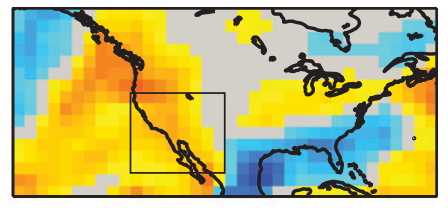

Control: Composite

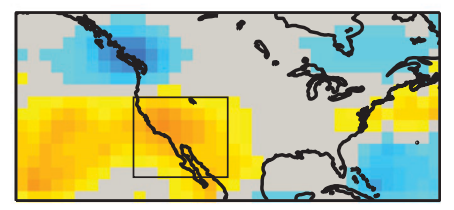

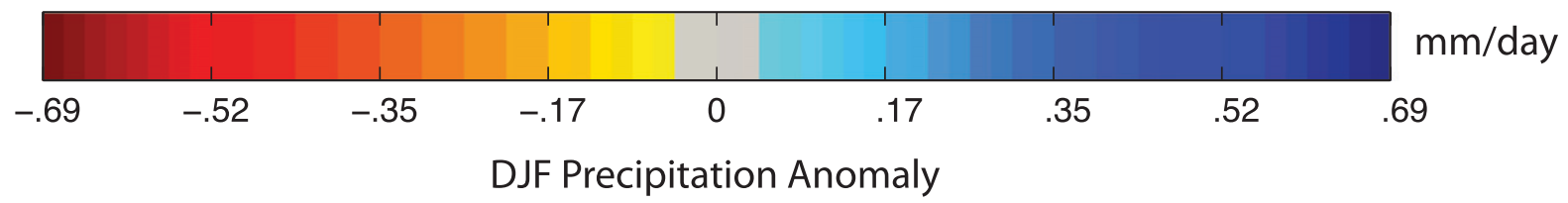

FIG. 6. Average DJF precipitation anomalies $\left(\mathrm{mm} \mathrm{day}^{-1}\right)$ for each of the five most extreme droughts ranked by drought density. Timeweighted composite averages for the forced and control simulations are also shown. Blue indicates above average precipitation and red below average precipitation. The square box is the NASW region.

and cool Atlantic Ocean SSTs. Like the tropical Pacific correlation, this is much weaker in the model.

\section{d. Dynamical diagnostics}

Not surprisingly, given the climatology of the NASW, negative December-February average (DJF) precipitation anomalies are the dominant cause of the annual soil moisture signal during NASW droughts. Figure 6 shows maps of the DJF precipitation anomalies during each of the five megadroughts in the forced and control simulations, as well as composites over all droughts. The spatial features are consistent within each of the droughts and between the forced and control simulations, with a positive precipitation anomaly in the Northwest (for all but the 784-804 control drought) while the NASW is anomalously dry. This structure is reminiscent of a La Niña winter moisture anomaly resulting from a northward shift of the storm track (e.g., Sarachik and Cane 2010).

Figure 7 shows the forced and control equatorial $\mathrm{Pa}$ cific zonal SST gradient index with the five largest drought periods identified in the corresponding NASW index highlighted in red [the gradient index was calculated by taking the difference between SSTs averaged in a western equatorial box of $5^{\circ} \mathrm{S}-5^{\circ} \mathrm{N}, 150^{\circ} \mathrm{E}-160^{\circ} \mathrm{W}$ and an eastern equatorial box of $5^{\circ} \mathrm{S}-5^{\circ} \mathrm{N}, 130^{\circ}-80^{\circ} \mathrm{W}$ 

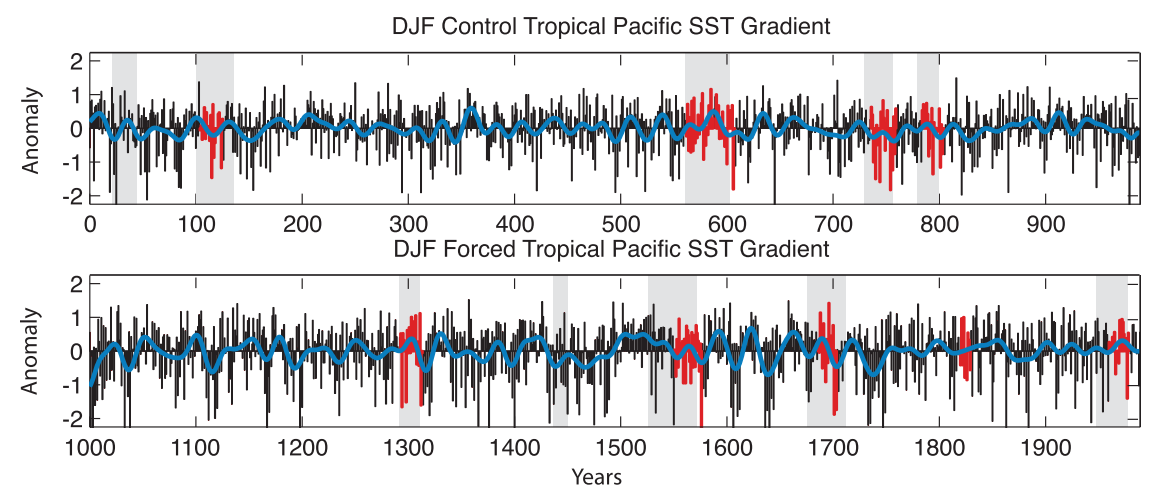

FIG. 7. DJF equatorial Pacific zonal SST gradient anomaly $\left({ }^{\circ} \mathrm{C}\right)$ for the forced and control runs calculated using the zonal SST gradient index defined in Karnauskas et al. (2009). The five largest drought periods as determined from the NASW soil moisture index and by using the 2S2E and MH06 definitions are highlighted in red or gray shading, respectively. The sixth-century drought is actually two droughts that were split by the $2 \mathrm{~S} 2 \mathrm{E}$ drought definition.

following Karnauskas et al. (2009)]. Considering the evidence for synchronous phasing between La Niña states and negative NASW soil moisture periods on both interannual and decadal-to-multidecadal time scales (in observations) one might expect the drought periods to be coincident with the largest positive excursions in the gradient index (the most La Niña-like state). This is not the case, however, and the state of the tropical Pacific does not appear to have a consistent and strong control over simulated low-frequency drought periods in the NASW (only the late-thirteenth- and twentieth-century forced droughts and the late-sixth-century control drought correspond to persistent La Niña states). Low-frequency ENSO variability is, therefore, not the only mechanism driving persistent moisture anomalies in the NASW in the ECHO-G model. Similar analyses of both the Pacific decadal oscillation (PDO), the leading principal component of monthly SST anomalies in the North Pacific Ocean poleward of $10^{\circ} \mathrm{N}$ (Zhang et al. 1997), and the Atlantic multidecadal oscillation (AMO), the 10-yr running mean of Atlantic SST anomalies north of the equator (Enfield et al. 2001) indices, suggests that these oscillations exert a similarly weak influence on modeled NASW hydroclimate (both were analyzed as in Fig. 7; the low-pass correlation between NASW drought and the PDO and AMO indices are given in Table 2). Furthermore, there is very little consistency outside of the NASW region in the seasonal and annual mean model fields of temperature and evaporation during drought periods. By contrast, the winter half-year average [November-April (NDJFMA)] SLP field shows a high pressure anomaly over the North $\mathrm{Pa}$ cific during nearly all of the megadroughts (Fig. 8). This is consistent with a northward shift of the storm track. For the forced simulation, the hemispherically symmetric SLP anomaly in the composite is reminiscent of La Niña, but the individual droughts tend not to exhibit characteristic ENSO-driven SLP symmetry. In the control run, the composite and individual drought patterns are even less characteristic of ENSO variability, suggesting that stochastic Northern Hemisphere atmospheric variability can drive persistent NASW drought in the model. Although the Arctic Oscillation (AO), defined as the leading mode of the monthly mean wintertime SLP following Thompson and Wallace (1998), is more tightly coupled to both the forced and control soil moisture index (Table 2) than the corresponding ENSO, PDO, or AMO indices, the correlation is still weak. It is therefore likely that the stochastic variability associated with the simulated decadal-length droughts in the NASW is the result of numerous atmospheric modes that are not readily described using a single atmospheric index. Given the very consistent spatial structure of the precipitation anomalies and the above characterization of SLP anomalies, our collective analysis suggests that stochastic atmospheric variability can produce persistent northward shifts of the storm track in the ECHO-G simulated climate, similar to those seen during La Niña events, and thus drive megadrought occurrences in the model.

TABLE 2. Ten-year low-pass correlation coefficients between the AMO, PDO, and AO indices and NASW box average soil moisture in the ECHO-G forced and control simulations.

\begin{tabular}{lccc}
\hline \hline & AMO index & PDO index & AO index \\
\hline Forced & -0.087 & 0.052 & -0.212 \\
Control & 0.012 & -0.010 & -0.149 \\
\hline
\end{tabular}


Forced: 1686-1703

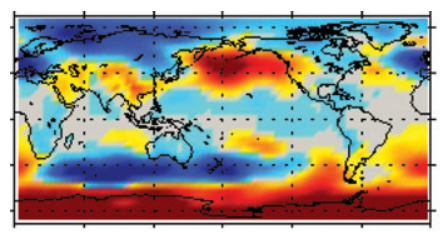

Forced: 1293-1313

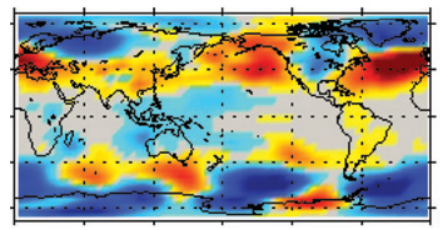

Control: $736-759$

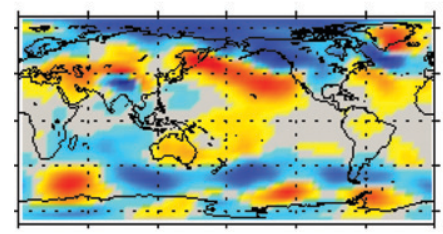

Control: $590-607$

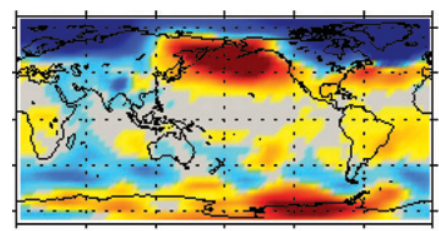

Forced: 1960-1978

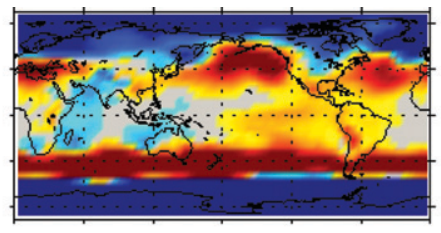

Forced: $1820-1829$

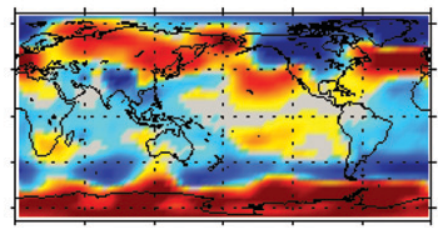

Control: $562-587$

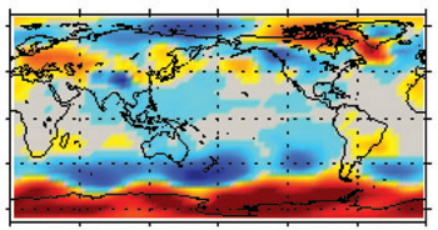

Control: $104-125$

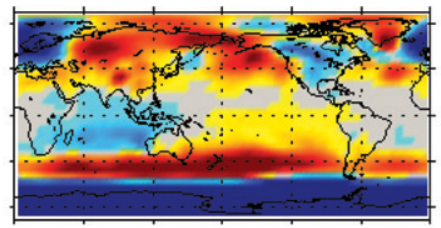

Forced: 1551-1576

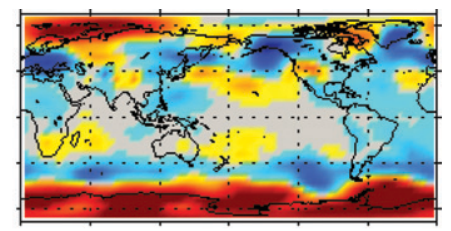

Forced: Composite

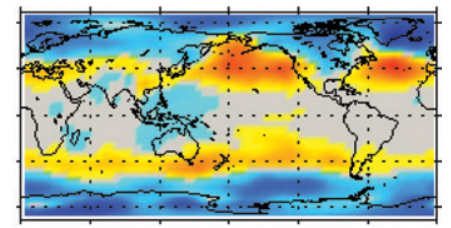

Control: 784-804

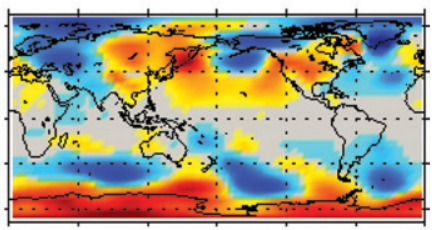

Control: Composite

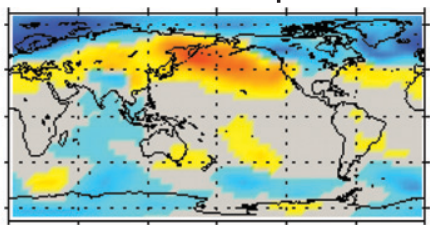

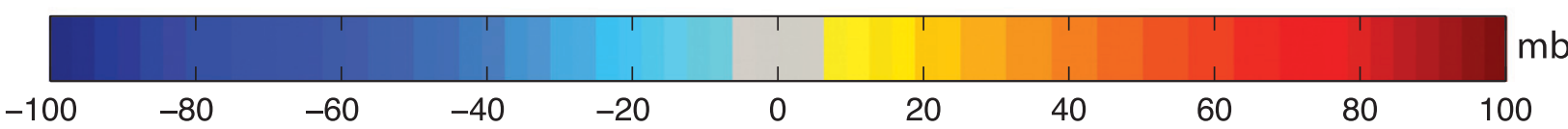

FIG. 8. Winter (Nov-Apr) SLP anomalies $(\mathrm{mb})$ for each of five droughts identified using the 2S2E identification metric and the composites over all the drought years for the forced and control runs.

\section{Conclusions}

Megadroughts in the North American southwest, in forced and control simulations using the ECHO-G AOGCM, are similar in duration and magnitude to those seen in the paleoclimate record. The droughts in the forced simulation are not, however, temporally synchronous with those in the proxy record or the forcing time series, nor are there significant differences between the drought features simulated in the forced and the control runs. This indicates that model-simulated megadroughts can result from internal variability of the modeled climate system, rather than as a response to changes in exogenous forcing variations. The frequency and persistence of megadroughts in the model and North American Drought Atlas suggests that mechanisms beyond first-order autoregressive variability are producing these drought features. Although the ECHO-G AOGCM is capable of simulating megadroughts through a persistent anomalous SST forcing in the tropical $\mathrm{Pa}-$ cific (e.g., one in the late-sixth-century drought in the control run and one in the late-thirteenth-century drought in the forced run), other mechanisms can produce similarly extreme moisture anomalies in the NASW in the model. In particular, the lack of low-frequency coherence between NASW soil moisture and other modeled fields and the PDO, AMO, and AO indices during identified drought periods suggests that stochastic atmospheric variability can contribute significantly to the occurrence of simulated megadroughts in the NASW. These results, while limited to a single model, demonstrate the importance of analyzing both forced and 
control simulations in concert with the paleoclimate record. Stochastic variability has been shown to drive drought in models on interannual to decadal time scales, particularly in weakly teleconnected regions by Hunt (2011). In this instance, it seems plausible that stochastic atmospheric variability in the ECHO-G model can produce storm track shifts (and associated hydroclimatic changes like NASW drought) that are uninterrupted by tropical Pacific influence because of the weak NASWENSO teleconnection on multidecadal time scales.

In the observational record, persistent droughts in the NASW have all been tied to cool tropical Pacific SSTs (e.g., Seager et al. 2005; Herweijer et al. 2006), but it is not known if this relation holds for the entire last millennium. Consequently, these model results have two implications depending on whether the modeled hydroclimate variability is a reasonable representation of the actual climate system: 1) if the model is accurately simulating real-world variability, then stochastic atmospheric variability and ENSO both appear capable of producing persistent droughts in the NASW or 2), if the model is misrepresenting the actual variability, then this feature is a likely component of AOGCMs that will influence future projections of hydroclimate, an inaccuracy that must be addressed when assessing model projections. One possible explanation for point two is that a weak teleconnection between the NASW and the tropical Pacific Ocean in the model allows atmospheric variability to drive droughts, whereas the tighter link to the Pacific in nature ensures that megadroughts are more strongly forced by tropical Pacific SST anomalies. Additionally, there is observational evidence that warm tropical Atlantic SSTs can create a tendency toward dry conditions in the NASW (Seager et al. 2008b; Kushnir et al. 2010; Nigam et al. 2011) and this has been appealed to as a cause of medieval megadroughts (Feng et al. 2008; Oglesby et al. 2011). The connection of the NASW drought index in the model to the Atlantic is weaker than observed and this too could allow atmospheric variability to exert a stronger relative influence on NASW hydroclimate.

Longer records of proxy-estimated tropical Pacific SST (e.g., Emile-Geay et al. 2013) are necessary to assess the state of ENSO during megadroughts and to determine how coherent previous NASW drought and ENSO variability may have been prior to the observational record. In the meantime, additional analyses of AOGCM simulations will identify what produces modelsimulated megadroughts and help evaluate model treatment of regional low-frequency hydroclimate variability. In particular, a model intercomparison employing multiple AOGCMs is necessary to determine if stochastic atmospheric variability similarly influences NASW megadrought occurrences in the most recent generation of AOGCMs. This will be possible as an increasing number of last-millennium simulations from the Paleoclimate Modelling Intercomparison Project 3 (PMIP3)/ phase 5 of the Coupled Model Intercomparison Project (CMIP5) archive (Taylor et al. 2011) become available. The analyses in this paper are thus a proposed framework for assessing model performance with regard to hydroclimate variability and for performing comparisons to paleoclimate data in future multimodel comparisons.

Acknowledgments. SC, JES, and RS are supported by the NOAA Award Global Decadal Hydroclimate Variability and Change (NA10OAR431037). RS was also supported by NSF Award ATM09-02716 and NOAA Award NA08-OAR4320912. BIC was supported by the NSF Award North American Megadroughts: Atmosphere-Ocean Forcing and Landscape Response from the Medieval Period to the Near-Term Greenhouse Future (ATM-0902716). JFGR was supported by MMAMRM-200800050084028//200800050083542, MCIN-CGL2008-06558-C02-01, and UCM/921407. Crosswavelet and wavelet coherence software was provided by A. Grinsted.

\section{REFERENCES}

Burgman, R., R. Seager, A. Clement, and C. Herweijer, 2010: Role of tropical Pacific SSTs in global medieval hydroclimate: A modeling study. Geophys. Res. Lett., 37, L06705, doi:10.1029/ 2009GL042239.

Burke, E. J., and S. J. Brown, 2008: Evaluation uncertainties in the projection of future drought. J. Hydrometeor., 9, 292299.

Cobb, K. M., C. D. Charles, H. Cheng, and R. L. Edwards, 2003: El Ninõ-Southern Oscillation and tropical Pacific climate during the last millennium. Nature, 424, 271-276.

Cook, B. I., R. Seager, R. L. Miller, and J. A. Mason, 2013: Intensification of North American megadroughts through surface and dust aerosol forcing. J. Climate, 26, 4414-4430.

Cook, E. R., R. Seager, M. A. Cane, and D. W. Stahle, 2007: North American drought: Reconstructions, causes, and consequences. Earth Sci. Rev., 81 (1-2), 93-134.

,,-- R. R. Heim, R. S. Vose, C. Herweijer, and C. A. Woodhouse, 2010: Megadroughts in North America: Placing IPCC projections of hydroclimatic change in a long-term paleoclimate context. J. Quat. Sci., 25, 48-61, doi:10.1002/ jqs. 1303.

Dai, A., K. E. Trenberth, and T. R. Karl, 1998: Global variations in droughts and wet spells: 1900-1995. Geophys. Res. Lett., 25, 3367-3370.

— - - and T. Qian, 2004: A global dataset of Palmer drought severity index for 1870-2002: Relationship with soil moisture and effects of surface warming. J. Hydrometeor., 5, 1117-1130.

Dümenil, L., and E. Todini, 1992: A rainfall-runoff scheme for use in the Hamburg climate model. Adv. Theor. Hydrol., 9, 129-157. 
Emile-Geay, J., K. Cobb, M. Mann, and A. T. Wittenberg, 2013: Estimating central equatorial Pacific SST variability over the past millennium. Part II: Reconstructions and implications. J. Climate, 26, 2329-2352.

Enfield, D. B., A. M. Mestas-Nunez, and P. J. Trimble, 2001: The Atlantic multidecadal oscillation and its relation to rainfall and river flows in the continental US. Geophys. Res. Lett., 28 , 2077-2080.

Feng, S., R. J. Oglesby, C. M. Rowe, D. B. Loope, and Q. Hu, 2008: Atlantic and Pacific SST influences on medieval drought in North America simulated by the Community Atmospheric Model. J. Geophys. Res., 113, D11101, doi:10.1029/ 2007JD009347.

González-Rouco, J. F., H. Beltrami, E. Zorita, and H. Von Storch, 2006: Simulation and inversion of borehole temperature profiles in surrogate climates: Spatial distribution and surface coupling. Geophys. Res. Lett., 33, L01703, doi:10.1029/ 2005 GL024693.

$\longrightarrow, \ldots, \ldots$, and M. B. Stevens, 2009: Borehole climatology: A discussion based on contributions from climate modeling. Climate Past, 5, 97-127.

Graham, N. E., and Coauthors, 2007: Tropical Pacific-mid-latitude teleconnections in medieval times. Climatic Change, 83, 241285.

Herweijer, C., R. Seager, and E. R. Cook, 2006: North American droughts of the mid to late nineteenth century: A history, simulation and implication for mediaeval drought. Holocene, 16, 159-171.

,,--- , and J. Emile-Geay, 2007: North American droughts of the last millennium form a gridded network of tree-ring data. J. Climate, 20, 1353-1376.

Hunt, B. G., 2011: Global characteristics of pluvial and dry multiyear episodes with emphasis on megadroughts. Int. J. Climatol., 31, 1425-1439.

Kaplan, A., M. A. Cane, Y. Kushnir, A. C. Clement, M. B. Blumenthal, and B. Rajagopalan, 1998: Analyses of global sea surface temperature 1856-1991. J. Geophys. Res., 103 (C9), 18567-18589.

Karnauskas, B. K., R. Seager, A. Kaplan, Y. Kushnir, and M. A. Cane, 2009: Observed strengthening of the zonal sea surface temperature gradient across the equatorial Pacific Ocean. J. Climate, 22, 4316-4321.

— J. E. Smerdon, R. Seager, and J. F. González-Rouco, 2012: A Pacific centennial oscillation predicted by coupled GCMs. J. Climate, 25, 5943-5961.

Kushnir, Y., R. Seager, M. Ting, N. Naik, and J. Nakamura, 2010: Mechanisms of tropical Atlantic SST influence on North American hydroclimate variability. J. Climate, 23, 56105628.

Legutke, S., and R. Voss, 1999: The Hamburg atmosphere-ocean coupled general circulation model-ECHO-G. Deutsches Klimarechenzentrum Rep., 62 pp.

Mann, M. E., and J. M. Lees, 1996: Robust estimation of background noise and signal detection in climatic time series. Climatic Change, 33, 409-445.

Meehl, G. A., and A. Hu, 2006: Megadroughts in the Indian monsoon region and southwest North America and a mechanism for associated multidecadal Pacific sea surface temperature anomalies. J. Climate, 19, 1605-1623.

Milly, P. C. D., and K. A. Dunne, 2010: On the hydrologic adjustment of climate-model projections: The potential pitfall of potential evapotransporation. Earth Interact., 15. [Available online at http://EarthInteractions.org.]
Min, S.-K., S. Legutke, A. Hense, and W.-T. Kwon, 2005a: Internal variability in a 1000 -yr control simulation with coupled climate model ECHO-G-1. Near-surface temperature, precipitation and mean sea level pressure. Tellus, 57A, 605621.

,,$-- \ldots$, and -2005 b: Internal variability in a $1000-\mathrm{yr}$ control simulation with coupled climate model ECHO-G-2. El Niño Southern Oscillation and North Atlantic Oscillation. Tellus, 57A, 622-640.

Nigam, S., B. Guan, and A. Ruiz-Barradas, 2011: Key role of the Atlantic multidecadal oscillation in 20th century drought and wet periods over the Great Plains. Geophys. Res. Lett., 38, L16713, doi:10.1029/2011GL048650.

Oglesby, J. R., S. Feng, Q. Hu, and C. Rowe, 2011: Medieval drought in North America: The role of the Atlantic multidecadal oscillation. PAGES News, Vol. 19, No. 1, PAGES International Project Office, Bern, Switzerland, 18-19.

Pachauri, R. K., and A. Reisinger, Eds., 2007: Climate Change 2007: Synthesis Report. IPCC, 104 pp.

Sarachik, E. S., and M. A. Cane, 2010: The El Niño-Southern Oscillation Phenomenon. Cambridge University Press, 369 pp.

Schlenker, W., W. M. Hanemann, and A. C. Fisher, 2007: Water availability, degree days, and the potential impact of climate change on irrigated agriculture in California. Climatic Change, 81, 19-28.

Schubert, S. D., M. J. Suarez, P. J. Pegion, R. D. Koster, and J. Bacmeister, 2004a: Causes of long-term drought in the U. S. Great Plains. J. Climate, 17, 485-503.

$-,-,-1,-\ldots$, and J. Bacmeister, 2004b: On the cause of the 1930s Dust Bowl. Science, 303, 1855-1859.

Seager, R., and G. Vecchi, 2010: Greenhouse warming and the 21st century hydroclimate of southwestern North America. Proc. Natl. Acad. Sci. USA, 107, 21256-21262.

_ , Y. Kushnir, C. Herweijer, N. Naik, and J. Velez, 2005: Modeling of tropical forcing of persistent droughts and pluvials over western North America: 1856-2000. J. Climate, 18, 4065-4088.

— , and Coauthors, 2007: Model projections of an imminent transition to a more arid climate in southwestern North America. Science, 316, 1181-1184.

— R. Burgman, Y. Kushnir, A. Clement, E. Cook, N. Naik, and J. Miller, 2008a: Tropical Pacific forcing of North American medieval megadroughts: Testing the concept with an atmosphere model forced by coral-reconstructed SSTs. J. Climate, 21, 6175-6190.

_- Y. Kushnir, M. Ting, M. A. Cane, N. Naik, and J. Velez, 2008b: Would advance knowledge of 1930s SSTs have allowed prediction of the Dust Bowl drought? J. Climate, 21, 32613281.

Sheffield, J., E. F. Wood, and M. L. Roderick, 2012: Little change in global drought over the past 60 years. Nature, 491, 435 438.

Stevens, M. B., J. E. Smerdon, J. F. González-Rouco, M. Stieglitz, and H. Beltrami, 2007: Effects of bottom boundary placement on subsurface heat storage: Implications for climate model simulations. Geophys. Res. Lett., 34, L02702, doi:10.1029/ 2006 GL028546.

Stine, S., 1994: Extreme and persistent drought in California and Patagonia during medieval time. Nature, 369, 546-549.

Taylor, K. E., R. J. Stouffer, and G. A. Meehl, 2011: A summary of the CMIP5 experiment design. World Climate Research Programme Rep., 33 pp. [Available online at http://cmip-pcmdi. llnl.gov/cmip5/docs/Taylor_CMIP5_design.pdf.] 
Thompson, D. W. J., and J. M. Wallace, 1998: The Arctic Oscillation signature in the wintertime geopotential height and temperature fields. Geophys. Res. Lett., 25, 1297-1300.

Thornthwaite, C. W., 1948: An approach toward a rational classification of climate. Geogr. Rev., 38, 55-94.

von Storch, H., E. Zorita, J. M. Jones, Y. Dimitriev, F. GonzalezRouco, and S. F. B. Tett, 2004: Reconstructing past climate from noisy data. Science, 306, 679-682.

Woodhouse, C. A., and J. T. Overpeck, 1998: 2000 years of drought variability in the central United States. Bull. Amer. Meteor. Soc., 79, 2693-2714.
Zhang, Y., J. M. Wallace, and D. S. Battisti, 1997: ENSO-like interdecadal variability: 1900-93. J. Climate, 10, 1004-1020.

Zorita, E., F. González-Rouco, and S. Legutke, 2003: Testing the Mann et al. (1998) approach to paleoclimate reconstructions in the context of a 1000-yr control simulation with the ECHO-G coupled climate model. J. Climate, 16, 13781390.

, J. F. González-Rouco, H. von Storch, J. P. Montávez, and F. Valero, 2005: Natural and anthropogenic modes of surface temperature variations in the last thousand years. Geophys. Res. Lett., 23, L08707, doi:10.1029/2004GL021563. 